\title{
Atividade antimicrobiana da nanopartícula de prata incorporada a resinas compostas na Odontologia Restauradora: revisão integrativa
}

Antimicrobian activity of the silver nanoparticle incorporated to composite resins in Restorative Dentistry: integrative review Actividad antimicrobiana de la nanopartícula de plata incorporada a resinas compuestas en Odontología Reconstructiva: revisión integrativa José Ruan Cunha CORREIA

Centro Universitário Católica de Quixadá, 63900-257 Quixadá - CE, Brasil https://orcid.org/0000-0002-6251-8783

Karlos Eduardo Rodrigues LIMA

Centro Universitário Católica de Quixadá, 63900-257 Quixadá - CE, Brasil https://orcid.org/0000-0003-3127-9772 Marcelo Victor Sidou LEMOS Universidade de Fortaleza, Fortaleza - CE, Brasil https://orcid.org/0000-0002-2993-534X

Érika Matias Pinto DINELLY

Centro Universitário Católica de Quixadá, 63900-257 Quixadá - CE, Brasil https://orcid.org/0000-0003-2786-3132

Natasha Muniz FONTES

Centro Universitário Católica de Quixadá, 63900-257 Quixadá - CE, Brasil https://orcid.org/0000-0002-0502-0364

Talita Arrais Daniel MENDES

Programa de Pós Graduação em Odontologia da Universidade Federal do Ceará, 60020-181 Fortaleza - CE, Brasil https://orcid.org/0000-0003-3519-3618

\section{Resumo}

Objetivo: revisar a literatura de forma integrativa para o estudo da atividade antibacteriana de compósitos resinosos com nanopartículas de prata incorporadas em sua composição. Metodologia: realizou-se três buscas distintas na literatura nas bases de dados Pubmed, Science Direct e Google Acadêmico, sendo que na primeira utilizou-se as palavras-chave "Antibacterials-agents, composite resins" na base de dados Pubmed, combinadas entre si pelo operador booleano "OR". Resultando em 52 estudos sem restrição de período que, após leitura crítica de títulos e resumos, selecionou-se 6 destes. Já no Science Direct, utilizou-se as palavras-chave "bacterial agentes" e "composite resins", combinadas pelo operador booleano "OR". Foram encontrados 110 estudos sem restrições de período que, após leitura crítica de títulos e resumos, selecionou-se 4. Por fim, no Google Acadêmico utilizou-se as palavras-chave "composite resins", "silver" e "atibacterial agentes" combinadas pelo operador booleano "AND", resultando em um total de 20 estudos, sem restrição de período, que após leitura criteriosa de títulos e resumos, selecionou-se 2. Resultados: Pode-se notar que com a implementação nanopartículas de prata em resinas compostas há um aumento significante na resistência contra Streptococus mutans e melhoras nas propriedades mecânicas destes materiais. Considerações finais: Os estudos comprovaram a eficácia da utilização das NP incorporadas em compósitos resinosos.

Descritores: Resinas Compostas; Nanopartículas; Antibacterianos.

\section{Abstract}

Objective: to review the literature in an integrative way to study the antibacterial activity of resin composites with silver nanoparticles incorporated in their composition. Methodology: there were three different searches in the literature in the databas es Pubmed, Science Direct and Google Scholar, and in the first, the keywords "Antibacterial agents, composite resins" were used in the Pubmed database, combined with each other by the Boolean operator "OR". It was resulted 52 studies without period restriction that, after critical reading of titles and abstracts, 6 of these were selected. In Science Direct, the keywords "bacterial agents" and "composite resins" were used, combined by the Boolean operator "OR". 110 studies were found without period restrictions that, after critical reading of titles and abstracts, were selected 4. Finally, in Google Scholar, the keywords "composite resins", "silver" and "antibacterial agents" combined by the Boolean operator "AND", resulting in a total of 20 studies, without period restriction, that after careful reading of titles and abstracts, 2 were selected. Results: it can be noted that with the implementation of silver nanoparticle in composite resins, there are a significant increase in resistance against Streptococus mutans and improvements in the mechanical properties of these materials. Final considerations: Studies have proven the effectiveness of using NP incorporated in resinous composites.

Descriptors: Composite Resins; Nanoparticles; Anti-Bacterial Agents.

\section{Resumen}

Objetivo: revisar la literatura de forma integradora para estudiar la actividad antibacteriana de los composites de resinas con nanopartículas de plata incorporadas en su composición. Metodología: se realizaron tres búsquedas diferentes en la literatura en las bases de datos Pubmed, Science Direct y Google Scholar, siendo la primera utilizando las palabras clave "Antibacterials-agents, composite resins" en la base de datos Pubmed, combinadas entre sí por el operador booleano "OR". Dando como resultado 52 estudios sin restricción de período que, tras la lectura crítica de títulos y resúmenes, se seleccionaron 6 de estos. En Science Direct, se utilizaron las palabras clave "agentes bacterianos" y "resinas compuestas", combinadas por el operador booleano "OR". Se encontraron 110 estudios sin restricciones de período que, luego de la lectura crítica de títulos y resúmenes, fueron seleccionados 4. Finalmente, en Google Scholar, las palabras clave "resinas compuestas", "plata" y "agentes atibacterianos" combinadas por el operador booleano "AND", dando como resultado un total de 20 estudios, sin restricción de período, que luego de una lectura cuidadosa de títulos y resúmenes, se seleccionaron 2. Resultados: se puede notar que, con la implementación de nanopartículas de plata en resinas compuestas, hay un aumento significativo de la resistencia contra Streptococus mutans y mejoras en las propiedades mecánicas de estos materiales. Consideraciones finales: Los estudios han demostrado la eficacia del uso de NP incorporados en composites resinosos.

Descriptores: Resinas Compuestas; Nanopartículas; Antibacterianos.

INTRODUÇÃO

Um sorriso estético se tornou algo almejado, sendo importante para a satisfação e bem-estar, desempenhando papel importante nas relações interpessoais, aumento da autoestima e melhor relacionamento social. Os compositos resinosos se tornaram populares na odontologia por ser um material estético e versátil, reabilitando com eficacia função e estética dentes danificados por processos cariosos $^{1}$. Tendo em vista os varios problemas inerentes a mecanismos de degradação, essas resinas composta podem ter sua meta de vida reduzida em cerca de 5 anos, consequências como fraturas e infiltrações, podem ser 
causadas pelo acumulo de biofilme, diminuindo assim a vida util do material ${ }^{2}$.

A utilização desses materiais tornou-se viável por apresentar em sua composição caracteristicas antimicrobianas e boa adesão dental, graças a utilização de sistemas adesivos $^{3}$. Muitas dessas restaurações com resinas se dão por conta da presença de cárie dentaria que é uma doença sistêmica multifatorial que irá provocar a desmineralização de contituintes dentários por ácidos produzidos pelo processo de fermentação de carboidratos por bacterias ${ }^{4}$. Tendo em vista que as leões cariosas são encontradas em grande escala, tornou-se necessário a utilização de um material restaurador com propriedades antimicrobianas, sendo viavel a utilização de nanoparticulas de prata para tal função ${ }^{5}$.

$\mathrm{O}$ acumulo de placa bacteriana tornou-se um desafio para utilização eficaz de resinas, podendo resultar em lesões periodontais e cáries secundárias, graças ao acumulo bacteriano. Portanto, a utilização de nanoparticulas de prata (NP) tornou-se uma opção viável para adicionar caracteristicas antimicrobianas aos compositos resinosos ${ }^{1}$.

Por mais que não exista total clareza no mecanismo de ação exato NPs, estas liberam íons de prata continuamente, causando eliminação de microorganismos devido a afinidade com enxofre e a sua atração eletrostatica, os íons de prata aderem a membrana citoplasmática, aumentando a permeabilidade, levando a ruptura do envelope bacteriano evitando também a síntese proteica ${ }^{6}$.

O ambiente bucal úmido pode afetar negativamente as propiedades do compositos resinosos, já que a sorção de água produz comprometimento da matriz polimera, influenciado diretamente as propiedades do material $^{7}$. A utilização da NP no entanto não é bem entendida e elucidada na pratica clínica, assim, tendo em vista essas circunstâncias o presente estudo objetiva revisar a literatura de maneira integrativa para avaliar as propiedades antimicrobianas de compositos resinos com a incorporação de NP.

MATERIAL E MÉTODO

O presente estudo visa revisar de forma integrativa a atividade antimicrobiana de compósitos resinosos com NP incorporadas em sua composição. A questão norteada da busca foi: os compósitos resinosos com implantação de NP apresentam atividade antimicrobiana? Descritores cadastrados no Mesh e Decs foram utilizados, juntamente com seus Entry Terms, a estratégia de busca está descrita na Tabela 1, baseando-se nos elementos do PICOT para uma revisão sistemática. População $(P)$ : Resinas compostas; Intervenção (I): O uso de NP como agente antibiótico incorporado em resinas compostas; Comparação (C): Grupo controle; Desfecho mais importante (O): ação antibacteriana da nanopartícula de prata; Tipos de estudos $(\mathrm{T})$ : estudos laboratoriais in vitro.

Tabela 1. Estratégia de busca nas bases de dados (Medical Subject Headings-Mesh)

\begin{tabular}{l} 
Medical Subject Headings-Mesh \\
\#1 (Silver) [Mesh] \\
\hline \#2 (Composite Resins) [Mesh] (Resins, Composite) \\
\hline \#3 (Anti-Bacterial Agents) [Mesh] (Agents, Anti-Bacterial) OR (Anti \\
Bacterial Agents) OR (Antibacterial Agents) OR (Agents, Antibacterial) \\
OR (Anti-Bacterial Compounds) OR (Anti Bacterial Compounds) OR \\
(Compounds, Anti-Bacterial) OR (Bacteriocidal Agents) OR (Agents, \\
Bacteriocidal) OR (Bacteriocides) OR (Anti-Mycobacterial Agents) OR \\
(Agents, Anti-Mycobacterial) OR (Anti Mycobacterial Agents) OR \\
(Antimycobacterial Agents) OR (Agents, Antimycobacterial) OR \\
(Antibiotics) OR (Antibiotic) \\
\hline \#4 busca \#1 AND \#2 AND \#3
\end{tabular}

\section{- Seleção dos Estudos}

Dois revisores independentes realizaram avaliação dos estudos encontrados e após a realização da estratégia de busca (Figuras 1 a 3 ) chegou-se a um total de 12 artigos elegíveis mediante os critérios de elegibilidade (Figura 4).

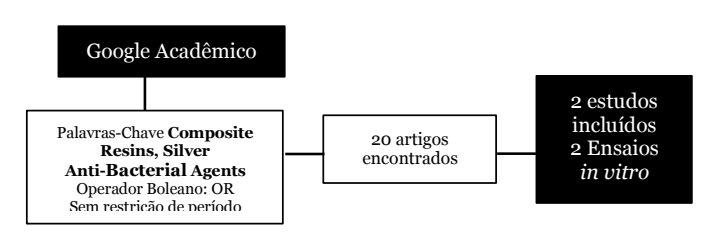

Figura 1: Fluxograma da busca na base de dados Google Acadêmico.

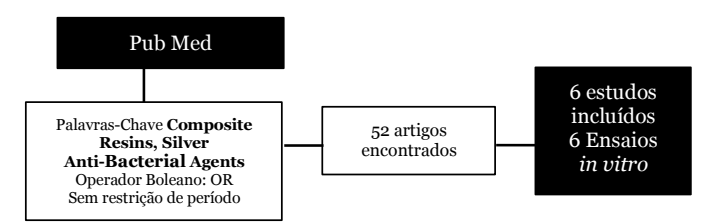

Figura 2: Fluxograma da busca na base de dados Pub Med.

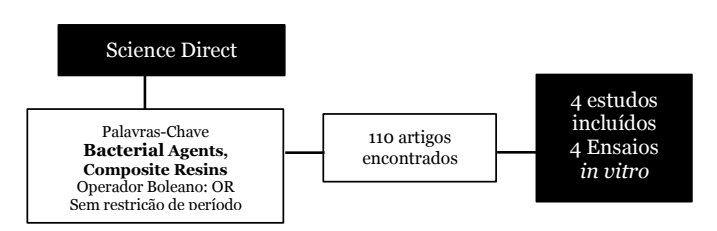

Figura 3: Fluxograma da busca na base dados Science Direct.

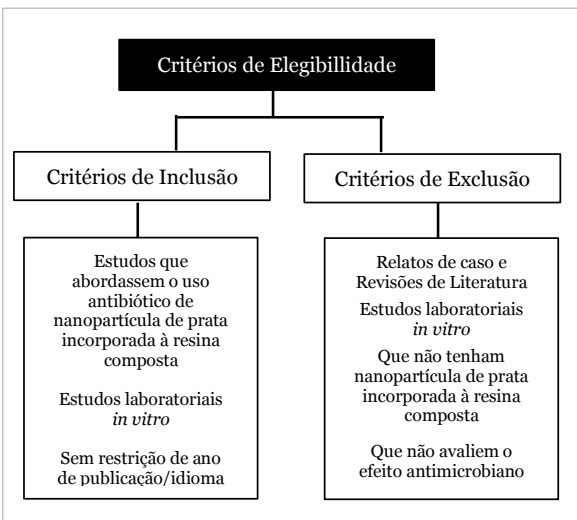

Figura 4: Critérios de elegibilidade. 


\section{RESULTADOS}

\section{Ao total das buscas realizadas foram selecionados 12 artigos de Ensaio in vitro (Tabela 2).}

Tabela 2: Estudos selecionados após aplicação dos critérios de inclusão.

\begin{tabular}{|c|c|c|c|}
\hline Autor/Ano & $\begin{array}{l}\text { Tipo de } \\
\text { estudo }\end{array}$ & Grupos/Métodos & Resultados \\
\hline $\begin{array}{c}\text { Yang et al. } \\
2015 .\end{array}$ & $\begin{array}{l}\text { Ensaio in } \\
\text { vitro }\end{array}$ & $\begin{array}{l}\text { Avaliada } \\
\text { bacteriana em doividade } \\
\text { grupos, sendo um com } \\
\text { compósitos } \\
\text { poliacrilamida (BC / } \\
\text { PAM) e outro com } \\
\text { compósitos } \\
\text { poliacrilamida com } \\
\text { nanoparticulas de prata } \\
\text { (BC- PAM AgNPs). }\end{array}$ & $\begin{array}{l}\text { O compósito } \\
\text { nanoparticulado BC- } \\
\text { AgNPs apresentou } \\
\text { microscopicamente } \\
\text { estrutura composta e } \\
\text { uniforme, apresentando } \\
\text { melhor resistência a } \\
\text { atividade bacteriana. }\end{array}$ \\
\hline $\begin{array}{c}\text { Xiao et al. }{ }^{1} \\
2019 .\end{array}$ & $\begin{array}{l}\text { Ensaio in } \\
\text { vitro }\end{array}$ & $\begin{array}{l}\text { Foram cultivadas três } \\
\text { espécies bacterianas e } \\
\text { testou-se a atividade } \\
\text { metabólica } \quad \text { em } \\
\text { diferentes compósitos } \\
\text { resinosos: } \\
\text { Grupo 1; Controle de R } \\
\text { enamel; Grupo } 2: \\
\text { Controle EM; Grupo } 3 \\
\text { ENMD; Grupo } 4 \\
\text { ENMD-o,12NAg. }\end{array}$ & $\begin{array}{l}\text { De todos os compósitos } \\
\text { analisados, a resistência } \\
\text { mecânica, resistência a } \\
\text { flexão e modulo de } \\
\text { elasticidade apresentaram } \\
\text { bons resultados, apenas o } \\
\text { compósito ENDM- } \\
\text { o,12NAg apresentou baixa } \\
\text { força flexural e módulo de } \\
\text { elasticidade. }\end{array}$ \\
\hline $\begin{array}{c}\text { Kasraei et al. } 4 \\
\quad 2014 .\end{array}$ & $\begin{array}{l}\text { Ensaio in } \\
\text { vitro }\end{array}$ & $\begin{array}{l}\text { Resina de nano-prata o\%, } \\
\text { Resina de nano-prata } 1 \% \text {, } \\
\text { Resina de nano-óxido de } \\
\text { zinco 1\% } \\
\text { Grupo controle (resina } \\
\text { flúida) } \\
\text { Noventa comprimidos } \\
\text { discoides contendo } \\
\text { partículas de } \% \% \text {, } 1 \% \text { de } \\
\text { nano-prata e } 1 \% \text { de nano- } \\
\text { oxido de zinco foram } \\
\text { preparados a partir de } \\
\text { resina composta fluida (n } \\
=30 \text { ). As propriedades } \\
\text { antibacterianas dos discos } \\
\text { de resina composta foram } \\
\text { avaliadas por teste de } \\
\text { contato direto. Soluçóes } \\
\text { diluídas de Streptococcus } \\
\text { mutans (PTCC 1683) e } \\
\text { Lactobacillus (PTCC 1643) } \\
\text { foram preparados. }\end{array}$ & $\begin{array}{l}\text { Os compósitos que } \\
\text { apresentavam nano } \\
\text { partículas de prata e nano } \\
\text { partículas de oxido de } \\
\text { zinco apresentavam boas } \\
\text { respostas em atividades } \\
\text { antimicrobianas contra } \\
\text { Streptococus mutans e } \\
\text { Lactobacillus que o grupo } \\
\text { de controle. }\end{array}$ \\
\hline $\begin{array}{l}\text { Melo et al. }{ }^{3} \\
2016 .\end{array}$ & $\begin{array}{l}\text { Ensaio in } \\
\text { Vitro }\end{array}$ & $\begin{array}{l}\text { Foram adicionados } \\
\text { agentes antibacterianos } \\
\text { nanoparticulados a base } \\
\text { de Metacrilato } \\
\text { (TBAEMA), } \\
\text { canfaroqiunona (CQ) e } \\
\text { prata (Ag) em três } \\
\text { compósitos distintos } \\
\text { para análise de } \\
\text { resistência mecânica e } \\
\text { antibacteriana. }\end{array}$ & $\begin{array}{l}\text { Os compósitos resinosos } \\
\text { que tiveram } \\
\text { devidição dos } \\
\text { apresentaram matérias, } \\
\text { resistência a fadiga boa } \\
\text { ligações resina-dentina e } \\
\text { todos apresentaram } \\
\text { resultados semelhantes e } \\
\text { positivos. }\end{array}$ \\
\hline $\begin{array}{c}\text { Cheng et al. } 9 \\
2012 .\end{array}$ & $\begin{array}{l}\text { Ensaio in } \\
\text { vitro }\end{array}$ & $\begin{array}{l}\text { Foram adicionadas } \\
\text { nanoparticulas } r \text { em } \\
\text { diferentes grupos } \\
\text { resinosos, tendo adição } \\
\text { de: Grupo 1 Brometo de } \\
\text { bis; Grupo } 2 \\
\text { dimetilamônio; Grupo } 3 \\
\text { Nanoparticulas de Prata } \\
\text { (NAg) para desenvolver } \\
\text { novos compósitos } \\
\text { nanoparticulados } \\
\text { antibacterianos. Testou- } \\
\text { se por teste } \\
\text { antimicrobiano contra } \\
\text { Streptococus mutans e } \\
\text { foram utilizados dois } \\
\text { compósitos comercias } \\
\text { comogrupo controle. }\end{array}$ & $\begin{array}{l}\text { O composto NAG + } \\
\text { QADM + NAg diminuiu } \\
\text { constantemente a } \\
\text { aderência de bactérias, já a } \\
\text { atividade metabólica e } \\
\text { produção de ácido lático } \\
\text { no composto NACP + } \\
\text { QADM +NAg foram muito } \\
\text { menores que nos } \\
\text { compostos comerciais. }\end{array}$ \\
\hline $\begin{array}{c}\text { Tanagawa et } \\
\text { al. } .^{10} 1999\end{array}$ & $\begin{array}{l}\text { Ensaio in } \\
\text { vitro }\end{array}$ & $\begin{array}{l}\text { Adicionou-se } \\
\text { nanopartículas de prata } \\
\text { (SSAM) em grupos } \\
\text { diferentes de resinas } \\
\text { compostas para analisar } \\
\text { a } \\
\text { antimicrobiana atividade } \\
\text { Streptococus mutans. } \\
\text { Grupo } 1 \text { composto de } \\
\text { resina com base de } \\
\text { TEGDMA-UDMA de } \\
49,5 \% \text { de TEGDMA; } \\
\text { Grupo } 2 \text { com resinas } \\
\text { com concentrações } \\
\text { diferentes de SiO2. }\end{array}$ & $\begin{array}{l}\text { Compósitos } \\
\text { concentrações maiores de } \\
\text { (SSAM) apresentaram boa } \\
\text { resistência contra o } \\
\text { Strptococus mutans, } \\
\text { mesmo com exposições de } \\
\text { até } 6 \text { horas, havendo } \\
\text { aumento no PH ácido } \\
\text { bacteriano. Os compósitos } \\
\text { com SiO2 presentes na } \\
\text { composição apresentaram } \\
\text { bons resultados nas } \\
\text { primeiras } 6 \text { horas de } \\
\text { exposição, mas não } \\
\text { diminuíram de forma } \\
\text { significativa a produção de } \\
\text { ácidos bacterianos. }\end{array}$ \\
\hline
\end{tabular}

Legenda: BC / PAM: compósitos com poliacrilamida, BC- PAM AgNPs: compósitos com poliacrilamida e nanoprata, NAg: nanoparticulas de prata, Z-250:base de metacrilato, P90: base de silorano, AgBr: Brometo de Prata, HNT: Nanotubetes de Hallosity. Ag+: Prata, SSAM: nanopartículas de prata, $\mathrm{SiO}^{2}$ : Dióxido de Silício

Fonte: Dados de pesquisa, 2021.
Tabela 2 (continuação): Estudos selecionados após aplicação dos critérios de inclusão.

\begin{tabular}{|c|c|c|c|}
\hline Autor/Ano & $\begin{array}{l}\text { Tipo de } \\
\text { estudo }\end{array}$ & Grupos/Métodos & Resultados \\
\hline $\begin{array}{c}\text { Silva et al. }{ }^{11} \\
2015 .\end{array}$ & $\begin{array}{l}\text { Ensaio in } \\
\text { vitro }\end{array}$ & 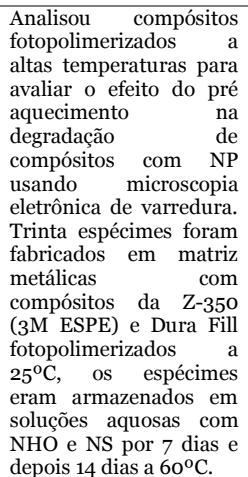 & $\begin{array}{lrr}\text { Os nanocompósitos } & \text { com } \\
\text { adição } & \text { de } & \text { NP } \\
\text { apresentaram } & \text { bons } \\
\text { resultados } & \text { com } & \text { a } \\
\text { exposição a } & \text { solução } \\
\text { aquosa nos primeiros } 7 & 7 \\
\text { dias, já a exposição a } 14 \\
\text { dias mitigou } & \text { os } \\
\text { compósitos, apresentando } \\
\text { modificações em sua } \\
\text { estrutura microscópica }\end{array}$ \\
\hline $\begin{array}{c}\text { Kasraei e } \\
\text { Azarsina }^{12} 2012\end{array}$ & $\begin{array}{l}\text { Ensaio in } \\
\text { vitro }\end{array}$ & $\begin{array}{l}\text { Partículas de nanoprata } \\
\text { foram adicionados aos } \\
\text { compósitos da Z- } \\
\text { 250(Base } \text { de } \\
\text { metacrilato) e P9o(A } \\
\text { base de silorano) a } 0,5 \% \\
\text { e } 1 \% \text { em peso para } \\
\text { analisar se a adição de } \\
\text { nanoprata a compósitos } \\
\text { com silorano e à base de } \\
\text { metacrilato afetam na } \\
\text { molhabilidade desses } \\
\text { materiais. Setenta e dois } \\
\text { discos foram preparados } \\
\text { e padronizados, sendo } \\
\text { separados em } 6 \text { grupos } \\
\text { contendo 12 amostras } \\
\text { cada. }\end{array}$ & $\begin{array}{l}\text { Nos espécimes com } \\
\text { compósitos resinosos com } \\
\text { P9o em sua composição, o } \\
\text { ângulo de contato com o } \\
\text { compósito ro foi } \\
\text { consideravelmente maior. } \\
\text { Portanto, a incorporação } \\
\text { de diferentes } \\
\text { concentrações de NP pode } \\
\text { diminuir a molhabilidade } \\
\text { de compósitos que } \\
\text { apresentam P9o em sua } \\
\text { composição. }\end{array}$ \\
\hline $\begin{array}{l}\text { Barot et al. }{ }^{13} \\
\quad 2020 .\end{array}$ & $\begin{array}{l}\text { Ensaio in } \\
\text { vitro }\end{array}$ & $\begin{array}{l}\text { Foram preparados } \\
\text { compósitos resinosos } \\
\text { (BIS-GMA/TEGDMA } \\
\text { relação 70\%/30\%) com } \\
\text { incorporação } r \text { de } \\
\text { nanotubets Halloysite } \\
\text { (HNT) para avaliar } \\
\text { quais efeitos o HNT } \\
\text { teria com as NAg. Os } \\
\text { compósitos } \\
\text { experimentais foram } \\
\text { divididos em seis } 6 \\
\text { grupos, um controle e } 5 \\
\text { com variação de massa } \\
\text { de } 1 \% \text { a } 10 \% \text { em peso de } \\
\text { HNT }\end{array}$ & $\begin{array}{l}\text { As frações de adição de } 1 \% \\
\text { a } 5 \% \text { de HNT/Ag em } \\
\text { compósitos resinosos, } \\
\text { aumentou sign } \\
\text { significativamente as } \\
\text { propriedades mecânicas } \\
\text { dos materiais. Enquanto a } \\
\text { adição de massa maiores } \\
\text { de HNT/AG de } 7,5 \% \text { e } \\
10 \% \text { não apresentaram } \\
\text { melhorias mecânicas nos } \\
\text { compósitos. }\end{array}$ \\
\hline $\begin{array}{c}\text { Fan et al. }{ }^{14} \\
2011 .\end{array}$ & $\begin{array}{l}\text { Ensaio } \\
\text { vitro }\end{array}$ & 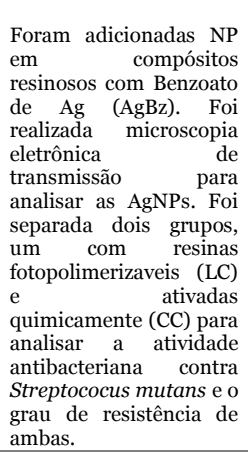 & $\begin{array}{l}\text { Nas resinas LC quanto mais } \\
\text { a concentraçôes de AgBz, } \\
\text { tornou-se mais difícil } \\
\text { fotopolimerizar as amostras } \\
\text { e em ambas as amostras de } \\
\text { resinas LC e CC, a maior } \\
\text { concentração de AgBz } \\
\text { causou um escurecimento da } \\
\text { cor das resinas. As resinas } \\
\text { com o,5\% de AgBz em sua } \\
\text { composição mostraram } \\
97,5 \% \text { de inibição contra } \\
\text { streptococus mutans, } \\
\text { mostrando que as } \\
\text { nanopartículas de prata, } \\
\text { mesmo em baixas } \\
\text { concentrações apresenta } \\
\text { boas } \\
\text { antibacterianas atividades } \\
\text { Streptococus mutans. contra }\end{array}$ \\
\hline $\begin{array}{c}\text { Jowkar et al. }{ }^{6} \\
2018 .\end{array}$ & $\begin{array}{l}\text { Ensaio } \\
\text { vitro }\end{array}$ & $\begin{array}{l}80 \text { terceiro molares } \\
\text { humanos } \\
\text { distribuídos hígidos, } \\
\text { aleatoriamente em } 8 \\
\text { subgrupos, armazenados } \\
\text { em cloramina o, } 5 \%-4^{\circ} \mathrm{C} \\
\text { por } 1 \text { mês até o uso. 40 } \\
\text { dentes foram preparados } \\
\text { para testes em esmalte e } \\
40 \text { dentes para testes em } \\
\text { dentina, ambas as } \\
\text { amostrar foram testadas } \\
\text { com resinas com } \\
\text { nanoprata rarar (SNPs), } \\
\text { partículas de oxido de } \\
\text { zinco (ZNPs) e } \\
\text { nanopartículas de dióxido } \\
\text { de titânio (TNPs). }\end{array}$ & $\begin{array}{l}\text { A adição de três } \\
\text { nanopartículas, não } \\
\text { apresentou efeitos } \\
\text { adversos nas amostras de } \\
\text { esmalte, não revelando } \\
\text { efeitos adversos no micro } \\
\text { cisalhamento. Não houve } \\
\text { diferença considerável } \\
\text { com a aplicação de três } \\
\text { nanopartículas nas } \\
\text { amostras de dentina e os } \\
\text { menores valores de } \\
\text { resistência a cisalhamento } \\
\text { foram encontrados nas } \\
\text { amostras que tiveram pré- } \\
\text { tratamento com TNPS. }\end{array}$ \\
\hline $\begin{array}{l}\text { Cao et al. }{ }^{15} \\
2017 .\end{array}$ & $\begin{array}{l}\text { Ensaio in } \\
\text { vitro }\end{array}$ & $\begin{array}{l}\text { Síntese de material a } \\
\text { base de resina composta } \\
\text { contendo AgBr e } \\
\text { (AgBr/BHPVP). }\end{array}$ & $\begin{array}{l}\text { A incorporação das } \\
\text { nanoparticulas } \\
\text { AgBr/BHPVP não afetou } \\
\text { força flexural e modulo } \\
\text { dos compósitos resinosos. } \\
\text { atividade antibacteriana. }\end{array}$ \\
\hline
\end{tabular}

Legenda: BC / PAM: compósitos com poliacrilamida, BC- PAM AgNPs: compósitos com poliacrilamida e nanoprata, NAg: nanoparticulas de prata, Z-250:base de metacrilato, P90: base de silorano, AgBr: Brometo de Prata, HNT: Nanotubetes de Hallosity. Ag+: Prata, SSAM: nanopartículas de prata, $\mathrm{SiO}^{2}$ : Dióxido de Silício Fonte: Dados de pesquisa, 2021. 
Pode-se notar que com a implementação de NP em compósitos resinosos, há um aumento significante na resistência contra Streptococus mutans e melhoras nas propriedades mecânicas destes materiais. Assim a utilização dessas nanopartículas proporciona melhor controle de biofilme, já que sua composição ajuda no equilíbrio de $\mathrm{PH}$. Em estudos já analisados anteriormente, a adição de outras partículas como a Hallosity proporciona uma resposta melhor ainda contra bactérias gram negativa e gram positivas.

Em contrapartida, outro estudo realizou a aplicação de NP em compósitos resinos com base de Silorano a 0,5\%, para obter melhores atividades antimicrobianas e resistência mecânica. Foi observado que os compósitos com base de Silorano a $0,5 \%$, quando adicionado partículas de Nanoprata (NP) apresentavam uma queda considerável na molhabilidade do material, havendo quedas consideráveis na qualidade. No estudo clínico foi observado diferentes amostrar com resinas compostas da Z250 com presença de Silorano e Metacrilato, foi observado que a implementação de diversas nanopartículas em um compósito resinoso pode comprometer algumas qualidades, como diminuição da molhabilidade do material.

DISCUSSÃO

No contexto atual de busca por saúde oral, diversos materiais vêm sendo desenvolvidos afim devolver função e saúde à cavidade oral, dessa forma, as NPs vêm sendo estudadas na literatura, assim sendo, ainda não existe um contexto eficaz no que tange sua eficácia antimicrobiana.

Assim, observa-se que Yang et al. ${ }^{8}$, por meio de um ensaio in vitro realizou um estudo com compósitos resinosos com presença de NP em sua composição, expondo estes a culturas de Strptococus mutans e lactobacillus, observando a partir de microscópios que a atividade da nanopartícula de prata faz com que haja liberação de íons $\mathrm{Ag}+$ constantemente, fazendo com que haja uma quebra na síntese molecular bacteriana, diminuindo a adesão do biofilme dental em restaurações com compósitos resinosos com NPs em sua composição. Dessa forma, tal incorporação em materiais restauradores pode ser de grande valia contra o processo carioso.

Por outro lado, Kasraei et al. ${ }^{12}$ analisaram que a adição de NP, nanopartículas de silorano e nanopartículas de metacrilato simultaneamente em um compósito, pode afetar algumas qualidades do material, como a molhabilidade, havendo diminuição da vida útil do material por conta do ângulo de contato do material e a estrutura dental estarem acima do recomendado. $O$ ângulo de contato dos compósitos com base de Silorano (P90) foram significativamente maiores por conta de características de hidrofobicidade presentes nas partículas de P90. Portanto, dependendo do tipo de compósito, a adição de NP em compósitos resinosos, podem causar um aumento no ângulo de contato desses materiais afetando na molhabilidade do material.

Contudo, Barot et al. ${ }^{13}$ analisaram a incorporação de nanotubetes da Hallosity (HNT) em diferentes concentrações (1\% a 10\%) em compósitos resinosos com concentrações de $70 \%$ e $30 \%$ (BIS-GMA e TEGDMA) e observou que as concentrações de $1 \%$ a $5 \%$ aumentaram significativamente as propriedades mecânicas, além de promover um aumento da resistência a atividade bacteriana contra Streptococus mutans dos materiais resinosos. Para isso, sabemos que a afinidade que os íons $\mathrm{Ag}^{+}$ liberados por compósitos contendo nanoprata em sua composição apresentam afinidade com - enxofre, causando um aumento na permeabilidade da membrana citoplasmática de agentes bacterianos como Streptococus mutans e lactobacillus, levando a ruptura do envelope bacteriano evitando a síntese proteica bacteriana.

Ainda, Tanagawa et al. ${ }^{10}$ realizaram um estudo onde adicionou NP em diferentes compósitos resinosos para analisar a atividade antibacteriana contra Streptococus mutans, separando em 2 grupos, onde um grupo seria composto de resina com base de TEGDMAUDMA de $49,5 \%$ de TEGDMA e o outro com resinas com concentrações diferentes de SiO2. Realizando exposições a Streptococus mutans por cerca de 6 horas o grupo 1 apresentou ótimos resultados, causando uma diminuição na produção de ácidos bacterianos, já os compósitos com óxido de silício em sua composição, apresentaram bons resultados depois de incorporadas partículas de SSMA, mas nas primeiras 6 horas não houve uma queda considerável na produção de ácidos bacterianos.

Já Yang et al. $^{8}$ realizaram um estudo onde foi coletado amostras de Gluconacetobacter xylinus e Staphylococcus para avaliar a resistência antimicrobiana em dois compósitos resinosos em dois grupos de compósitos nanoparticulados diferentes, compósitos com poliacrilamida (BC / PAM) e compósitos com poliacrilamida e prata (BCAgNPs). O compósito nanoparticulado BCAgNPs apresentou microscopicamente uma 
estrutura composta e uniforme, apresentando melhor resistência a atividade bacteriana.

Cheng et al. ${ }^{9}$ realizaram estudo onde foram adicionadas nanopartículas de Brometo de Bis, dimetilamônio e NPs para desenvolver novos compósitos resinosos com características antibacterianas. Os compósitos resinosos que tiveram nanopartículas de prata e dimetilamônio, causaram uma diminuição constante na aderência de placa bacteriana, já os compósitos resinosos que apresentavam em sua composição NPs e Brometo Bis em sua composição apresentaram atividade metabólica e produção de ácido lático bem menores que nos compostos comerciais.

Kasraei et al. ${ }^{4}$ realizaram pesquisa onde foi analisada a atividade antibacteriana de compósitos resinosos que apresentavam NP e nanopartículas de óxido de zinco em diferentes concentrações na sua composição. Os compósitos resinosos com a adição de NP e oxido de zinco apresentaram boas atividades antimicrobianas quando expostas a bactérias como Streptococus mutans e lactobacillus, impedindo a adesão de placa bacteriana e diminuindo a produção de ácido láctico.

Já Jowkar et al. ${ }^{6}$ analisaram a atividade de compósitos resinosos com implementação de NP em sua composição em esmalte dentário e em dentina. Quanto à atividade antibacteriana, os compósitos com NP, apresentaram ótimos resultados, sendo também realizados testes a resistência ao cisalhamento, os compósitos de esmalte e dentina não apresentaram efeitos adversos ao micro cisalhamento, pois, partículas $\mathrm{Ag}+$ proporcionam além de boas atividades antibacterianas, boas resistências a estresses mecânicos.

Contudo, Fan et al. ${ }^{14}$ realizaram estudo in vitro onde foram adicionadas NP em compósitos resinosos com Benzoato de $\mathrm{Ag}$ $(\mathrm{AgBz})$. Foi observado que nesses estudos realizou-se analise por microscopia eletrônica de transmissão. A atividade das NP é questionada, não só em compósitos fotopolimerizáveis, mas também em compósitos com polimerização química, foram separados dois grupos, uma com resinas fotopolimerizáveis (LC) e outro com resinas quimicamente ativadas (CC), para verificar a atividade antibacteriana contra strptococus mutans. Nas resinas LC, quanto maior a concentração de $\mathrm{AgBz}$, houve uma dificuldade na fotopolimerização, levando mais tempo e em ambas as amostras de resinas, a maior concentração de $\mathrm{AgBz}$ causou um escurecimento na cor das resinas. Foi possível observar que as resinas com $0,5 \%$ de $\mathrm{AgBz}$ em sua composição mostraram ótimos resultados, inibindo cerca de 97,5\% streptococus mutans, mostrando que as NP, mesmo em baixa concentrações, apresentam ótimas atividades antibacterianas.

Entretanto, Cao et al. ${ }^{15}$ desenvolveram um nanocompósitos a base de Brometo de Prata $(\mathrm{AgBr})$ e nanocompósitos de polímero fotopolimerizaveis (BHPVP). Embora a utilização de nanopartículas podem apresentar ótimos resultados em resistência e aitividades biológicas do materiais, no estudo, a implementação de $\mathrm{AgBr} / \mathrm{BHPVP}$ não apresentou aumento na resistência flexural de compósitos comercias, mas os compósitos que apresentavam $\mathrm{Ag}$ em sua composição, houve diminuição de ácidos lácticos bacterianos por conta da liberação constantes de partículas de $\mathrm{Ag}+$, impedindo a síntese molecular bacteriana.

Silva et al. ${ }^{11}$ avaliaram a reação de compósitos resinosos com nanoparticulas de prata $(\mathrm{Ag})$ em sua composição quando expostos pré-aquecimento de $25^{\circ} \mathrm{C}$ a $60^{\circ} \mathrm{C}$ em um intervalo de 7 a 14 dias e para avaliação foi utilizada microscopia eletrônica de varredura. A avaliação da resistência dos matérias deve ser certificada e avaliada quanto a sua qualidade em diferentes ambientes, as resinas Z-350 e Dura Fill foram armazenadas em soluções aquosas com Hidroxido de Sódio (NAOH) por 7 dias antes do uso.

Por fim, Melo et al. ${ }^{3}$, analisando a implementação de nanoparticulas não só $\mathrm{Ag}$ em compósitos resinosos, mas também nanoparticulas de metacrilato (TBAEMA) e canfaroquinona (CQ) observaram que as nanoparticulas que foram adicionadas em três materiais resinosos odontológicos diferentes para analisar a resistência antibacteriana, principalmente contra Streptococus mutans, mostraram boa resposta. Os materiais que apresentaram adição de Ag, TBAEMA e CQ, demonstraram boa resistência a fadiga resinadentina e resposta positiva aos testes de exposição a streptococus mutans, diminuindo significativamente a atividade antibacteriana, diminuindo a produção de ácidos equilibrando o $\mathrm{PH}$ graças a liberação constante de íon $\mathrm{Ag}+\mathrm{e}$ TBAEMA+.

\section{CONSIDERAÇÕES FINAIS}

Em suma, os compósitos resinosos que tiveram adição de NP apresentaram boas atividades antibacterianas, sendo materiais com resultados promissores para a odontologia restauradora, considerando que a atividade bacteriana pode comprometer restaurações e até diminuir sua vida útil por conta de infiltrações, causando cáries secundarias. 
Bactérias como Streptococus e lactobacillus estão então presentes no biofilme bacteriano, assim, em meio oral essas bactérias diminuem o $\mathrm{PH}$, causando desmineralização nos dentes e infiltrações em restaurações com materiais resinosos, causando cáries secundarias, então a utilização de NP melhora as qualidades antibacterianas dos materiais resinosos, graças a liberação constante de íons $\mathrm{Ag}+$ impedindo a proliferação moléculas bacteriana.

REFERÊNCIAS

1. Xiao $\mathrm{S}$, Wang $\mathrm{H}$, Liang $\mathrm{K}$, Tay $\mathrm{F}$, Weir MD, Melo MAS et al. Novel multifunctional nanocomposite for root caries restorations to inhibit periodontitis-related pathogens. J Dent. 2019;81:17-26.

2. Akan S, Torgut AG, Oktay $H$. Effects of malocclusions on facial attractiveness and their correlations with the divine proportion Auswirkungen von Malokklusionen auf die Gesichtsattraktivita "t und Korrelationen mit den Proportionen des Goldenen Schnitt. J Orofac Orthop. 2017;78(5):427-36.

3. Melo MAS, Orrego S, Weir MD, Xu HH, Arola DD. Designing multiagent dental materials for enhanced resistance to biofilm damage at the bonded interface. Interfaces ACS Appl Mater. 2016;11(8):11779-87.

4. Kasraei S, Sami L, Hendi S, Alikhani MY, Rezaei-Soufi L, Khamverdi Z. Antibacterial properties of composite resins incorporating silver and zinc oxide nanoparticles on Streptococcus mutans and Lactobacillus. Restor Dent Endod. 2014;39(2):109-14

5. Koidou VP, Chatzopoulos GS, Rosenstiel SF. Quantification of facial and smile esthetics. J Prosthet Dent. 2018;119(2):270-77.

6. Jowkar Z, Farpour N, Koohpeima F, Mokhtari MJ, Shafiei F. Effect of Silver Nanoparticles, Zinc Oxide Nanoparticles and Titanium Dioxide Nanoparticles on Microshear Bond Strength to Enamel and Dentin. J Contemp Dent Pract. 2018;19(11):1404-11.

7. Prajapati D, Nayak R, Pai D, Upadhya N, Bhaskar VK, Kamath P. Effect of resin infiltration on artificial caries: an in vitro evaluation of resin penetration and microhardness. Int J Clin Pediatr Dent. 2017; 10(3):250-56.

8. Yang G, Wang C, Hong F, Yang X, Cao Z. Preparation and characterization of BC/PAMAgNPs nanocomposites for antibacterial applications. Carbohydr Polym. 2015;115: 636-42.

9. Cheng L, Weir MD, Xu HHK, Antonucci JM, Kraigsley $\mathrm{AM}$, Lin $\mathrm{NJ}$, et al. Antibacterial amorphous calcium phosphate nanocomposites with a quaternary ammonium dimethacrylate and silver nanoparticle. Dental Mater. 2012; 28(5):561-72.
10. Tanagawa M, Yoshida $\mathrm{K}$, Matsumoto $\mathrm{S}$, Yamada T, Atsuta M. Inhibitory effect of antibacterial resin composite against Streptococcus mutans. Caries Res. 1999; 33(5):366-71.

11. Silva JC, Vieira RR, Rege ICC, Cruz CAS, Vaz LG, Estrela C, et al. Pre-heating mitigates composite degradation. J Appl Oral Sci. 2015;23(6):571-79.

12. Kasraei S, Azarsina M. The addition of silver nanoparticles reduces the wettability of methacrylate and composites based on from silorane. Braz Oral Res. 2012;26(6):505-10.

13. Barot T, Rawtani D, Kulkarni $P$. Physicochemical and biological assessment of silver nanoparticles immobilized Halloysite nanotubes-based resin composite for dental applications. Heliyon. 2020;6(3):e03601.

14. Fan C, Chu L, Rawls HR, Norling BK, Cardenas $\mathrm{HL}$, Whang K. Development of an antimicrobial resin-A pilot study. Dent Mater. 2011;27(4):322-28.

15. Cao W, Zhang Y, Wang X, Chen Y, Li Q, Xing $X$, et al. Development of a novel resin-based dental material with dual biocidal modes and sustained release of $\mathrm{Ag}+$ ions based on photocurable core-shell $\mathrm{AgBr} /$ cationic polymer nanocomposites. J Mater Sci Mater Med. 2017; 28(7):103.

\section{CONFLITO DE INTERESSES}

Os autores declaram não haver conflitos de interesse

\section{AUTOR PARA CORRESPONDÊNCIA}

\author{
Talita Arrais Daniel Mendes \\ Rua Monsenhor Furtado, S/N, Rodolfo Teófilo, \\ Fortaleza - CE, Brasil. CEP: 60430-355 \\ E-mail:talita_arrais@hotmail.com
}

